AperTO - Archivio Istituzionale Open Access dell'Università di Torino

\title{
Dynamics of Non-Equity Collaborations Among Small and Medium Enterprises
}

\section{This is the author's manuscript}

Original Citation:

\section{Availability:}

This version is available http://hdl.handle.net/2318/119633

since

Terms of use:

Open Access

Anyone can freely access the full text of works made available as "Open Access". Works made available under a Creative Commons license can be used according to the terms and conditions of said license. Use of all other works requires consent of the right holder (author or publisher) if not exempted from copyright protection by the applicable law. 


\title{
Dynamics of Non-Equity Collaborations Among Small and Medium Enterprises
}

\author{
Marco Remondino \\ SAA - School of Management \\ University of Turin \\ Torino, Italy \\ marco.remondino@gmail.com
}

\author{
Marco Pironti, Roberto Schiesari \\ e-business L@B \\ University of Turin \\ Torino, Italy \\ pironti@di.unito.it, schiesari@econ.unito.it
}

\begin{abstract}
A model is described and implemented, with the purpose of representing non-equity collaboration dynamics among small and medium enterprises (SMEs). In the real world these links are stable, but not strong. In this context the strong links are joint-ventures and participation exchanges, while non-equity collaboration (as a consortium) are stable, but leaving each enterprise as an autonomous entity. In particular, the governance of SMEs remains independent, but in the long term we observe a coevolution of strategies among the enterprises which take part in the collaborative network. These activities could be the basis for a network formation and/or impact the topology of an existing network. In this work an agent based model is introduced, aiming to explore the dynamics behind network formation among SMEs. (Abstract)
\end{abstract}

Keywords- Enterprise Collaboration, Network, Consortium, Agent Based Simulation (key words)

\section{INTRODUCTION}

The features of Socio-Economical environment in which the enterprise acts considerably affect its productive choices, the decisional models, internal organization and the relations with other enterprises. The key point of every Economical activity should be an aptitude to second and favour market changes.

Today, enterprises operate in dynamic markets where acquisition problems of productive factors constantly change along with the new technologies, customers' needs, peculiar features of demand in different sectors, internal situation of the enterprise (financial, economical and organizational), social conditions of the country, and so on.

Concentration is the typical phenomenon of present industrial society; the enterprises try to reach a more profitable dimension of their structures. Technical progress, media and transport improvement favour markets enlargement and increase general demand: this, in turn, is reflected by an increase of production and a search for the optimal size of competitors.

The goal is to create scale economies by subdividing the fixed production costs onto an ever increasing quantity of products, but also to gain advantages in purchases, integration of productive processes, production diversification, research of funding, creation of distribution process, limitation of competition. Not always, though, collaboration brings an effective improvement in Economical and Financial areas: by increasing enterprise dimensions, scale diseconomies could occur, like organizational inefficiencies, bureaucracy, managerial limits, overproduction and so on. This makes it necessary to modify the enterprise structure, by reducing or restructuring it, in order to make it economical.

Other elements that further accelerated this process, also in the sectors of services and commerce, are: the tendency towards a standardization in consumptions for industrialized countries, the incredible development of Information Technologies, the introduction of Euro currency. The mentioned sectors, during the past decades suffered less from the competition of multinational operators.

The small and medium enterprises (SMEs), that didn't achieve a dimension which could have allowed them to effectively compete with the multinational groups, had to look for aggregation forms. In this way, they could achieve scale economies to face competition, while keeping a certain level of independency. The driving factors behind the creation of links among autonomous enterprises have been: the search for an ideal dimension to compete on national and international markets and the desire to keep the ownership of the enterprises. At the beginning these collaborations among enterprises were unstructured configurations, but they soon evolved towards more complex and regulated forms, like consortiums.

The spreading of such collaboration forms, that were sometimes considered unfit for the scarce stability of links among the participants, didn't prevent the process of creation of entrepreneurship groups, formed by merger and acquisitions. This particularly happened in those sectors in which the opportunity of a strategic and operative centralized guidance, is higher.

Many operations of concentration among enterprises have been favored by the fact that many of them belonged to the same consortium; they have been able to know each other and to make some of their processes homogeneous and to analyze possible complementarities and synergies.

This kind of connections have been for the SMEs an effective way of successfully competing, while retaining a good degree of independence..

In order to empirically study how an enterprise network is formed among SMEs, an agent based model is used. Agent based simulation is an effective paradigm for studying 
complex systems. It allows the creation of virtual societies, in which each agent can interact with others basing on certain rules. In this way, a social system can be observed as if it were a laboratory study, by repeating the experiments all the needed times, and changing just some parameters, by leaving all the others still (coeteris paribus analysis), something that would be impossible in the real system. The agents are basic entities, endowed with the capacity of performing certain actions, and with certain variables defining their state. In the model presented here, the agents are reactive, meaning that they simply react to the stimuli coming from the environment and from other agents, without cognitively elaborating their own strategies. An agent based model consists of a multitude of software agents (both homogeneous or heterogeneous), each type being endowed with particular local properties and rules, put together within an environment, formally described as a set of parameters and rules. When the model is formally built and implemented, emergent results can be observed, thus inferring cause-effect relations by simulating different core scenarios.

In the present work, social network theory is briefly analyzed. Then, the comprehensive agent based model used is formally introduced, and it is discussed how it can be employed to study how a network among enterprises arises, when the firms individually do not feature a size allowing them to compete with the biggest companies. Some empirical results coming from the model are given and the future work in this direction is discussed.

\section{SOCIAL NETWORKS}

A social network is a social structure made of nodes (which are generally individuals or organizations) that are tied by one or more specific types of interdependency, such as values, visions, ideas, financial exchange, friendship. Social network analysis views social relationships in terms of nodes and ties. Nodes are the individual actors within the networks, and ties are the relationships between the actors. These concepts are often displayed in a social network diagram, where nodes are the points and ties are the lines.

The idea of drawing a picture (called a "sociogram") of who is connected to whom for a specific set of people is credited to. Moreno [33], an early social psychologist who envisioned mapping the entire population of New York City. Cultural anthropologists independently invented the notion of social networks to provide a new way to think about social structure and the concepts of role and position [38], an approach that culminated in rigorous algebraic treatments of kinship systems [34]. At the same time, in mathematics, the nascent field of graph theory [27] began to grow rapidly, providing the underpinnings for the analytical techniques of modern social network analysis. The strategic network perspective avers that the embeddedness of enterprises in networks of external relationships with other organizations holds significant implications for enterprise performance [25].

Specifically, since resources and capabilities such as access to diverse knowledge [9], pooled resources and cooperation [48], are often acquired through networks of inter-firm ties, and since access to such resources and capabilities influences enterprise performance [45], it is important from a strategy perspective to examine the effect of network structure on enterprise performance [23]. Relationships between enterprises and their partners affect enterprises' alliance-building, behaviour and performance [1] [39]. There is evidence that enterprises' network positions have an impact on their survival [4], innovativeness [1], market share and financial returns [41]. However, evidence remains mixed on which particular patterns of interorganizational relationships are advantageous for enterprises. One of the key ideas currently dominating the literature is Burt's [8] open network perspective, according to which an enterprise can obtain important performance advantages when exploiting relationships to partners that do not maintain direct ties among one another. The absence of direct ties among a firm's partners (the presence of structural holes) indicates that these partners are located in different parts of an industry network, that they are connected to heterogeneous sources of information, and that their invitations to jointly exploit business prospects present the focal enterprise with access to diverse deal-making opportunities [32]. Several studies have shown that enterprises improve their performance as a result of maintaining relationships, whereas other studies have shown negative performance effects of firms' maintaining positions in open networks [15].

The evidence reviewed shows that network configurations are dynamic and principally guided by the choices of partners and their network management capabilities and are beyond the direct influence of policy intervention. The evidence suggests that network infrastructures can have an indirect positive or negative impact on network configurations and can consequently encourage or hinder the development of certain forms of network relationships.

\section{A. Connections and link formations}

The tie formation represents the type of relationship among the actors thanks to the connection existence and the typology of the link, a small group of actors become a network. Many analysts adopt a "relational "or "social cohesion" approach that focuses on the direct and indirect connections among actors. There are two kind of approach that describe how the actors decide to start and develop the connection with other actors. First approach explains certain behaviors or processes through the fact of social connectivity itself, as well as through the density, strength, symmetry, rage, and so on, of the ties that bind firms' relationships may be symbiotic, the resources accessed and status obtained through one tie making ties with other firms possible and/or valuable [39] [45]. Partnering decisions are also influenced by strategic considerations such as the ability to play one partner off against another [9] [43] [48], the desire to create an appropriate mix of new and old ties [28] [7], or the need to maintain a manageable alliance portfolio size [30] and composition [17]. 
Another important line of network research employing relational analysis concerns itself with process of recruitment to social movements. Its point of departure is a study [44] that suggest how individuals with pre-existing with other actors are more likely to be contacted and recruited than individuals without such ties are; individual with few or weak ties to alternative networks are more likely to respond favourably to these recruitment efforts compared with individuals with strong commitments to countervailing network..

Within networks, the evolving pattern of relationships the network structure - shapes opportunities and constraints. Adopting Burt's definitions [10], the pattern of network ties surrounding social actors is a "causal spark" that can promote or hinder action. Networks take shape as actors enter into collaborative relations based on information about the quality, trustworthiness and status of potential partners obtained through experiences in their own and their partners' past relationships.

Partner selection research examines mechanisms of relationship formation and thus provides knowledge of how network structures emerge and change. In this context, firms treats partner selection as a risk-uncertainty problem. Specifically, firms' decision makers are conceived to follow a logic of reducing uncertainty and risk in their exchanges by engaging past partners in repeated ties and forming new ties with partners' partners based on referrals [37] [26], rather than seeking riskier and more uncertain non-local ties beyond these bounds [5] [29]. As a result of this preference for ties with past partners and their partners, firms' ties tend to congeal into dense, stable, and constraining local clusters [47] [24]. Thus, partner selection research tends to emphasize inertia in partner choice and network stabilizing mechanisms [12] [29].

Relatively partner selection several researches emphasize myopic partnering and network inertia [38] [12] [21]. However, decision makers do not inevitably reproduce their past relationships [2] [36]. As a result of its focus on the risk and uncertainty reduction partnering logic, partner selection research supplies few insights into the forces driving partner and network change. Baum et al. [6] attempted to generalize the risk-avoidance model of partner selection by adopting the performance feedback model from organizational learning to specify conditions under which risk-taking is more or less likely to occur, and thus the conditions under which firms' decision makers would select new partners and change their network.

Consistent with learning theory predictions, the risk and uncertainty avoidance pattern of partnering with past partners and their partners was more likely when firm reached its performance aspirations, but more likely to select partners with which it had no prior direct or indirect contact when performance fell below aspirations, or greatly exceeded them.

Study of tie dissolution is needed to augment models of network dynamics, as the implications of partnering patterns will remain clear until termination patterns are better understood [42].

\section{B. Local links and clusters}

Local link formation implies that new partners are found through an actors' existing network and that the new partners is already known to other partners "in the neighborhood". The overall network structure resulting from local link formation is a network composed of dense "cliques" of actors, which indicates that they are highly connected to each other. Having a more central and autonomous structural position in a network provides firms with access to resources, learning opportunities and reduces uncertainty. Regarding the formation of new linkages Gulati [22] finds that the process of new tie creation is heavily embedded in an actors' existing network: this means that new ties are often formed with prior partners or with partners of prior partners, indicating network growth to be a " local” process, where strategic collaboration are path dependant [34]. Particularly when considering inter-firm alliances, new link formation is considered "risky business" and actors prefer alliances that are embedded in a dense clique were norms are more likely to be enforceable and opportunistic behaviour to be punished [22] [39] [20] [3].

However, distant link formation implies that new linkages are created with partners whom are not known to the existing partners of an actor. In the social sciences, Grannovetter [19] was the first to differentiate between local ties in dense cliques (strong ties) and distant ties that bridge these cliques (weak ties). More precisely, the author argue that distant linkages "serve as crucial functions in linking otherwise unconnected segment of the network" [18]. At the level of the firm, Burt [9] shows that distant linkages that serve as bridges between dense local cliques of firms, can provide access to new source of information and favourable strategic negotiations positions ("structural holes"), which improves the firms" position in the network and industry.

\section{Strenght of weak ties}

"The strength of weak ties," is the title of a 1973 article by Granovetter [18]: weak ties as a concept describes the nature of a relationship between nodes in terms of the consequences for an entire network. Hence "weak ties" serves as a bridge between concepts that describe relationships and those that describe entire networks. Perhaps the most authoritative statement of the idea is Granovetter's 1982 reprise [19]. “...Our acquaintances ("weak ties”) are less likely to be socially involved with one another than are our close friends ("strong ties"). Thus the set of people make up on any individual and his acquaintances will constitute a low-density network (one in which many of the possible ties are absent), whereas the set consisting of the same individual and his close friends will be densely knit. Ego will have a collection of close friends, most of whom are in touch with one another - a dense "clump" of social structure. Ego will [also] have a collection of acquaintances, few of whom know one another. Each of these acquaintances, however, is likely to have close friends in his or her own right and therefore to be enmeshed in a closely knit clump of social structure, but one different from Ego’s...”. 
Weak ties have two characteristics:

weak ties facilitate the flow of information from otherwise distant parts of a network;

weak ties help to integrate social systems.

We will analyze each details.

1)Weak ties facilitate the flow of information from otherwise distant parts of a network: individuals with few weak ties will be deprived of information from distant parts of the social system and will be confined to the provincial news and views of their close friends.

2) Weak ties help to integrate social systems: social systems lacking in weak ties will be fragmented and incoherent. New ideas will spread slowly, scientific endeavours will be limited and subgroups that are separated by race, ethnicity, geography or other characteristics will have difficulty reaching a modus vivendi [19].

The importance of weak ties is asserted to be that. This ties are disproportionately likely to be bridges as compared to strong ties, which should be underrepresented in that role. This does not preclude the possibility that most weak ties have no such function. It must be the case that (1) something flows through these bridges - they actually serve as conduits bearing information and influence to groups they otherwise would not get, and (2) whatever it is that flows actually plays some important role in the network. A flow can occur only under some circumstances. Passing along information or exercising influence should not be too costly to the weak tie that constitutes the bridge, otherwise, strong ties that are willing to bear the cost will be more effective in making the bridge.

Granovetter's [18] [20] influential "strength of weak ties" thesis maintains that weak ties are often more important in spreading information or resource because they tend to serve as bridges between otherwise disconnected social group; strong ties lead to less efficient transmission processes because a large number of actors in the strong tie network also know each other, as well as knowing the focal actor.

To clarify the relevance of tie strength it will be useful to consider two dimension social relationships: information and influence. Collaboration thus requires, first and foremost, that corporate actors have access to information. Consistent with the "strength-of weak ties' thesis, both the transmission rate and availability of such disparate information will be higher for individuals relying on weak network ties rather than strong ties.

\section{From weak ties to clustering}

Within a social network, enterprises can generate clusters characterized by stronger ties

Clustering is definable as the tendency of vertically and/or horizontally integrated firms in related lines of business to concentrate geographically, or, to a more general extent, virtually [11].

Cluster policies are an example of pro-active industrial policy with shared responsibilities among actors; besides, the agglomeration of firms and their suppliers can confer competitive advantage to the enterprises involved.
There are many social and economic reasons leading to clusters creation. The main economic drivers of cluster formation in particular industries include [14]:

proximity to markets. Despite low-cost international transportation, being near to markets can be important in cluster development (products that are not easy to transport, that require continuous interaction with customers).

Supplies of specialised labour. The existence of specialised pools of labour, such as occur around many universities.

Presence of input and equipment suppliers. A high frequency of exchanges between co-located capital goods producers and users.

Availability of specific natural resources.

Economies of scale in production. Such economies may allow only a small number of efficient-scale plants in a given market.

Availability of infrastructure. Some types of infrastructure may also be quite specific, such as with certain transport or tourist facilities, further encouraging agglomeration.

Low transaction costs. When firms and their suppliers operate near to each other, and the frequency of interaction is high, the costs of negotiation and contract enforcement may be reduced.

As a consequence, there is an improvement of information access. This is straightforward: when many enterprise are integrated, than the information system is usually shared or, if individually managed, it allows an easier communication among them. Enterprises, when aggregated in clusters, can share, for example: product and market information, product design, marketing policies, training, recruitment services, human resources, skills, purchasing (lower prices for raw material and supplies), transportation and delivery (for geographical clusters), quality control, testing facilities, financing (credit guarantees at collective level), sponsorships [49]. Many of the mentioned can be considered as "competences". That's why the model takes as its basic unit for link creation the generic "competence exchange" among two enterprises. Of course this is true during the external exploration phase, where an enterprise is looking for the best partner to create a new link, or to strengthen an existing one. Though, also the internal exploration is very important since it can allow an enterprise to develop a new competence, that will be used later on to be exchanged, thus constituting a new link with another firm [31].

The price-independent preferences of both the market and its participants are based on each ones perception of the other rather than the market simply being the sum of all its participants actions as is usually the case. So, the cluster effect is a usually cited example of emergence.

\section{NON EQUITY COLLABORATIONS: CONSORTIUM IN ITALIAN EXPERIENCE}

Before Non equity organizations (consortiums in various juridical forms) are one of the most widely used ways for 
setting up formalized collaborations among the enterprises that aim to share resources and results, with the goal of reaching economies of scale (both financial and related to knowledge).

A consortium has the goal of creating value for the enterprises part of it, even when they also have external activities and create product and services not only for the other participants.

The choice of formalizing collaborations derives from some basic choices and reasons; the opportunity of disposing of a structure which is co-participated by others, on which to converge financial resources, both immaterial and material ones, where these are significant.

Another important element is the need of creating rules for controlling the contributions of associates, and the benefits to be divided among them, along with rights and modes for material and non material assets to be gained.

When collaborative forms get more significant and pervasive for the value chain, the enterprises should count on clear and well defined rules, able to reinforce the trust towards the consortium and the associates.

These fundamental aims are to keep into the highest consideration when managing consorted forms since, if they are perceived as not properly correspondent or protected by the consortium they could bring to situations of crisis, with consequences in terms of efficacy and efficiency or even with the risk of dissolution of the consortium itself [13].

The advantages that enterprises, especially if small and medium dimensions, can derive from non equity forms of collaboration lie in the possibility of using the consorted form to share investments, higher external visibility and share and leverage reciprocal knowledge.

When facing deep changes in the competitive scenarios, that require an higher innovation and internationalization to compete successfully, the more pro-active SMEs [46] search for collaborative forms that, though preserving as much as possible their independence, allow them to react to the challenges of the globalization.

It is possible to observe that many investments made by consortiums among SMEs are mainly centered - particularly in recent years - on fields considered more risky, since characterized by an higher intangible content (e.g. research and development, promotion of collective brands, internationalization projects and so on).

These investments are less easily accessible by individual SMEs, both for the high financial amount and for the higher difficulties in obtaining funds with the usual forms of getting into debts. The financial constrain often represents a non negligible problem for SMEs, when facing medium term investment programs, considered at high risk, for which it's difficult to set "asset financing” operations.

Besides in some countries, like Italy, non equity forms like consortiums can have some financial and fiscal facilitations.

Being able to share operative and financial risks, by reaching a critical mass of investments, allowing the enterprises to pursue the creation of strategic intangible resources in their industries is a primary goal in formalized forms of cooperation, but in order to realize efficient programs it is necessary to have a common orientation to address resources and strengths towards goals with returns that are not necessarily in the short period, thus supporting the risk.

Non equity forms also have among their primary goals that of realizing a politics of knowledge management, facilitating the bi-directional flows both between the consortium and its associates, and among the associates themselves. Consortiums also feature some points of weakness, that could invalidate their efficiency and the capability to evolve in line with the needs of the market in which they operate.

An issue is that of the short term orientation. The links within a consortium are often weaker than equity ones, and this can bring to decisions oriented to the short term, in order to get a wider consensus and avoid the recess of the participants, thus scarifying longer term programs.

In order to limit such problematic it's advisable an accurate selection of the participants and, in order to keep common strategic orientations, the creation of statutory rules that punish opportunistic behaviors or situations of decisional stall.

Another limit is the need of having a wide consensus among the associates to take decisions, with insufficient proxy for managerial organisms. This limit is embedded into many non equity organizations, since the convinced adhesion of a significant part of the associates is appropriate so that, also individually, they carried on what decided and designed for the whole consortium.

If the associates perceive the consortium as a distant reality or merely prescriptive, they could slow down or compromise the realization of common strategies or worsen the image of the alliance, also abroad, as a strategic group.

In order to conjugate a wide consensus and decisional rapidity the consortium should have clear and accepted rules, but it's also necessary that an effective communication strategy is carried on for strategies and activities.

Trust is an essential value for "hyperarchic" organizations [16], both towards the directional organisms and towards other participants to the consortium. This kind of trust regards various aspects, among which also the expectations about the life-span of the consortium itself, that shouldn't be lower than the time needed to realize the set goals.

A rule system that, even allowing flexibility and dynamism to the individual enterprises, could sanction opportunistic behaviors - that would harm the consortium can contribute to keep an atmosphere of reciprocal trust. The enterprises accept to give sensible information, to delegate strategic functions of their value chain, if and only if the trust is not mined.

A controversial topic about non equity links is about their capability of facilitating integrations among the associates, with the typical M\&A dynamics.

Belonging to the same consortium can actually facilitate the aggregation among the associates, to the extent of creating real clusters. The main reasons are:

the higher knowledge created among the participants, compared to that towards external enterprises 
a wider process uniformity among the consorted enterprises, that usually is realized with the adoption of common procedures, suppliers, technology and brands

the interest of the whole consortium if favoring integration process among associates, in order to avoid the acquisition by other external enterprises

The two initial motivations especially regard the reduction of informative asymmetries and the reduction of costs and risks of the integration process, that are among the most frequent causes of failure for M\&A operations.

Speaking about the interest of the consortium in keeping knowledge, market and financial resources within its structure, this strategy finds a counter altar in the opportunity of avoiding dimensional imbalance, that would affect the governance.

The two opposed needs find realization in rules that, on the one side make easier such operations among the associates, when compared to those regarding external player. On the other side they avoid that the excessive contractual and corporative power of a consortium could lower the sense of belonging for those associates that are not the bigger ones.

\section{The Agent Based ModeL}

The model has been developed by prof. Marco Pironti and dr. Marco Remondino, at the e-Business L@B, University of Turin. It is built in pure Java, thus following the Object Oriented paradigm. This is particularly suitable for agent based modelling, since the individual agents can be seen as objects coming from a prototypal class, interacting among them basing on the internal rules (methods). While the reactive nature of the agents may seem a limitation, it's indeed a way to keep track of the aggregate behaviour of a large number of entities acting in the same system at the same time. All the numerical parameters can be decided at the beginning of each simulation (e.g.: number of enterprises, and so on).

Everything in the model is seen as an agent; thus we have three kinds of agents: Environment, Enterprises and Emissaries $\left(E^{3}\right)$. This is done since each of them, even the environment, is endowed with some actions to perform.

\section{A. Heat Metaphor}

In order to represent the advantage of an enterprise in owning different competences, the "heat" metaphor is introduced. In agent based models for Economics, the metaphor based approach [40] is an established way of representing real phenomena through computational and physical metaphors. In this case, a quantum of heat is assigned for each competence at each simulation turn. If the competence is internal (i.e.: developed by the enterprise) this value is higher. If the competence is external (i.e.: borrowed from another enterprise) this value is lower. This is realistic, since in the model we don't have any form of variable cost for competencies, and thus an internal competence is rewarded more. Heat is thus a metaphor not only for the profit that an enterprise can derive from owning many competences, but also for the managing and synergic part (e.g.: economy of scale). Heat is also expendable in the process of creating new internal competences (internal exploration) and of looking for partner with whom to share them in exchange of external competences (external exploration). At each time-step, a part of the heat is scattered (this can be regarded as a set of costs for the enterprise). If the individual heat gets under a threshold, the enterprise ceases its activity and disappears from the environment.

At an aggregate level, average environmental heat is a good and synthetic measure to monitor the state of the system.

The environment is regarded as a meta-agent, representing the world in which the proper agents act. It's considered an agent itself, since it can perform some actions on the others and on the heat. If features the following properties: a grid $(\mathrm{X}, \mathrm{Y})$, i.e.: a lattice in the form of a matrix, containing cells; a dispersion value, i.e.: a real number used to calculate the dissipated heat at each step; the heat threshold under which an enterprise ceases; a value defining the infrastructure level and quality; a threshold over which new enterprises are introduced; a function polling the average heat (of the whole grid). The environment affects the heat dispersion over the grid and, based on the parameter described above, allows new enterprises to join the world.

\section{B. Enterprises}

This is the most important and central type of agent in the model. Its behaviour is based on the reactive paradigm, i.e.: stimulus-reaction. The goal for these agents is that of surviving in the environment (i.e.: never go under the minimum allowed heat threshold). They are endowed with a heat level (energy) that will be consumed when performing actions. They feature a unique ID, a coordinate system (to track their position on the lattice), and a real number identifying the heat they own. The most important feature of the enterprise agent is a matrix identifying which competences (processes) it can dispose of. In the first row, each position of the vector identifies a specific competence, and is equal to 1 , if disposed of, or to 0 if lacking. A second row is used to identify internal competences or outsourced ones (in that case, the ID of the lender is memorized). A third row is used to store a value to identify the owned competences developed after a phase of internal exploration, to distinguish them from those possessed from the beginning. Besides, an enterprise can be "settled", or "not settled", meaning that it joined the world, but is still looking for the best position on the territory through its emissary. The enterprise features a wired original behaviour: internally or externally explorative. This is the default behaviour, the one with which an enterprise is born, but it can be changed under certain circumstances. This means that an enterprise can be naturally oriented to internal explorative strategy (preferring to develop new processes internally), but can act the opposite way, if it considers it can be more convenient. While in the present model the agents are stochastic (with a different 
probability distribution decided at the beginning of the simulation for the two agents' classes), cognitive agents will be added shortly, using reinforcement learning techniques to optimize their behaviour and make it more realistic.

Finally, the enterprise keeps track of its collaborators (i.e.: the list of enterprise with whom it is exchanging competencies and making synergies) and has a parameters defining the minimum number of competencies it expects to find, in order to form a joint. The main goal for each enterprise is that of acquiring competences, both through internal (e.g.: research and development) and external exploration (e.g.: forming new links with other enterprises). The enterprises are rewarded with heat based on the number of competences they possess (different, parameterized weights for internal or external ones), that is spread in the surrounding territory, thus slowly evaporating, and is used for internal and external exploration tasks.

\section{Emissaries}

These are agents that strictly belong to the enterprises, and are to be seen as probes able to move on the territory and detect information about it. They are used in two different situation: 1) if the enterprise is not settled yet (just appeared on the territory) it's sent out to find the best place where to settle. 2) If the enterprise is already settled and chooses to explore externally, an emissary is sent out to find the best possible partners. In both cases, the emissary, that has a field of vision limited to the surrounding 8 cells, probes the territory for heat and moves following the hottest cells. When it finds an enterprise in a cell, it probes its competencies and compares them to those possessed by its chief enterprise verifying if these are a good complement (according to the parameter described in the previous section). In the first case, the enterprise is settled in a cell which is near the best enterprise found during the movement. In the second case, the enterprise asks the best found for collaboration). A link is created among two enterprises if at least one competence may be exchanged among them. Be $\mathrm{CM}(\mathrm{a})$ the competences missed by enterprise a, and CM(b) those missed by enterprise $b$, the exchanged number of competences will be the minimum between CM(a) and $\mathrm{CM}(\mathrm{b})$. The strength of the link among two enterprises will be proportional to the number of exchanged competences, and will vary during the simulation (e.g.: after enterprise a acquires a new competence that $b$ is missing and vice versa). While moving, the emissary consumes a quantum of heat, that is directly dependant on the quality of infrastructures of the environment.

\section{Main Iterations}

The main iterations for the simulation model are described in this section.

At step 0 , a lattice is created $(\mathrm{X}, \mathrm{Y})$. A number $\mathrm{n}$ of enterprises are created, $\mathrm{k}$ of them internally explorative and $\mathrm{n}-\mathrm{k}$ of them externally explorative. $\mathrm{X}, \mathrm{Y}, \mathrm{n}$, and $\mathrm{k}$ are set by the user, before the simulation starts.
At step 1, the environment checks if some enterprise reached the minimum heat threshold; if so, removes it from the world. After that, each enterprise, if idle (not doing anything) decides what behaviour to follow.

At step 2, all the enterprises that selected to be EE move their emissary by one cell. All the IE ones work on the R\&D cycle (one step at a time).

At step 3, the EE enterprises check if the emissary finished its energy and, in that case, ask the best found enterprise for collaboration (they can receive a positive or negative reply, based on the needs of the other enterprise). The IE enterprises check if $R \& D$ process is finished and, in that case, get a competence in a random position (that can be already occupied by an owned competences, thus wasting the work done).

At step 4, the environment scatters the heat according to its parameters. Loop from step 1.

\section{QUALITATIVE RESUltS}

While the main object of this paper is to present the model itself as a tool for studying the aggregation into networks of SMEs, in the present paragraph some insights will be given about preliminary results obtained from the model itself. The presented ones will be mainly qualitative results, although the model can give many quantitative individual and aggregate results.

The model can give the following different kinds of outputs, when running in "normal" mode:

1) a real-time graph, depicting the social network, in which the nodes are the enterprises, whose colour represent the behaviour they are following at a given step, and the links are the ties indicating two or more enterprises mutually exchanging one or more competences.

2) A set of charts, showing in real time some core parameters, namely: average heat in the environment, number of links (in the network), number of links (average), number of enterprises doing internal exploration, number of ceased enterprises since the beginning, number of born enterprises since the beginning, number of available competences (overall), total number of skills possessed at the beginning, obtained by external exploration, obtained by internal exploration. 


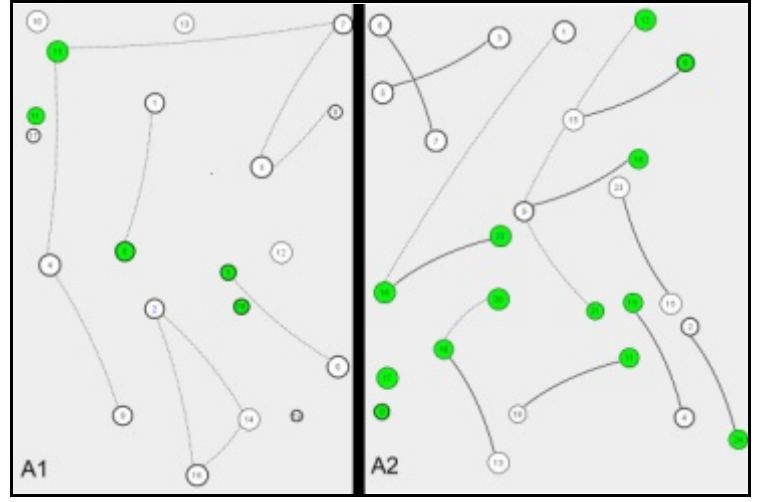

Figure 1. Figure 1: Network formation

In figure 1, an existing district is analyzed (A1); the enterprises are mainly small sized ones, and some collaborations already exist. The evolution (A2) is carried on by the model, by considering the introduction of new players in the market. Since internal research and development is often too expensive for SMEs, the tendency is that of creating new links thus creating a cluster, in which the enterprises exchange their competences. Though, they remain autonomous, in the sense that no enterprise is acquired by another one.

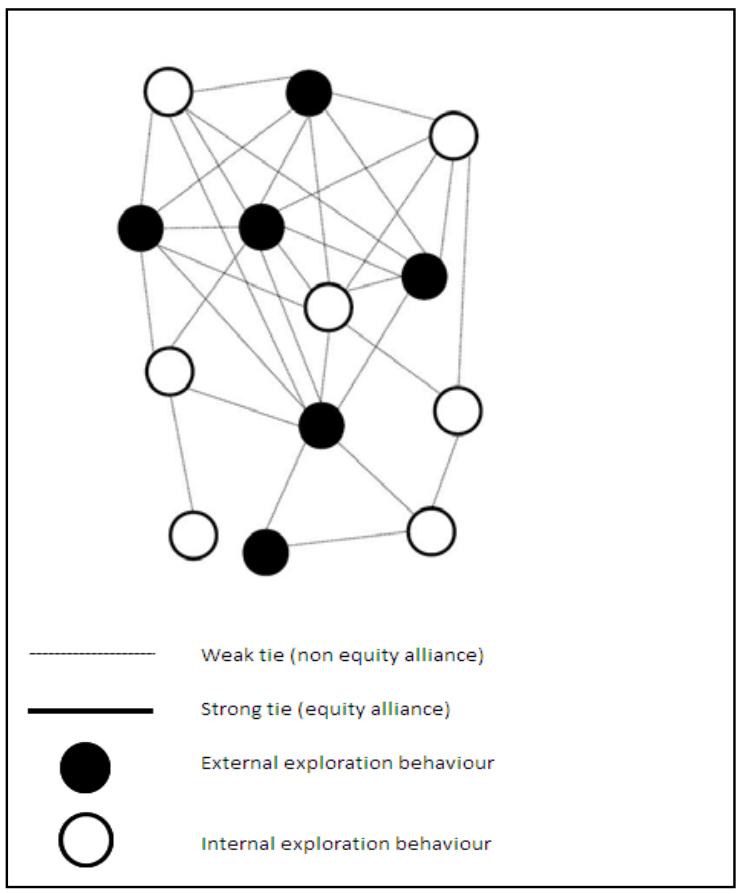

Figure 2. Figure 2: Many non-equity links

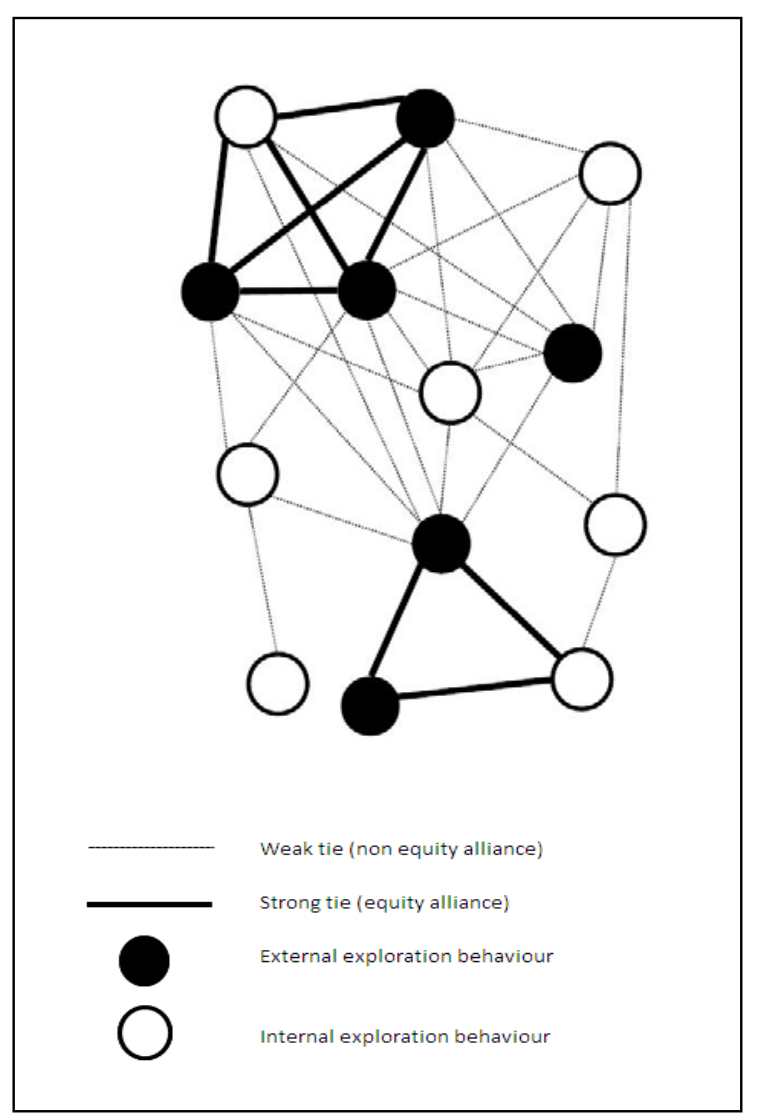

Figure 3. Figure 3: Same scenario after 2 simulated years

\section{CONCLUSION}

Small and medium enterprises often have to face the fierce competition coming from bigger and wealthier companies. One of the most effective policies to overcome this threat is that of organizing themselves into networks and clusters, while maintaining a good level of independency.

The second aspect regards spending resources like time and money: the development of new internal processes is usually time and resource consuming and is difficult to attain, especially when referring to radical cases. Though, SMEs often build a network for competences exchange among them, and a very important variable when considering the strategies performed by an enterprise; once possessed, the advantage can be exploited or shared. In the first case, the enterprise can gain customers and money, by being the only one (or among the few ones) possessing it. But it risks to lose its advantage as soon as other players can develop it. Another strategy is that of sharing the process innovation, in exchange for other competencies and/or money.

Non equity forms of collaboration, realized through formalized structures (like consortiums) can carry on an important function for SMEs competitiveness.

The growing competition, introduced by market globalization, is an important motivation to realize 
aggregative forms that, by preserving the independence of individual enterprises, allow to make less penalizing the limits due to the small dimension and consequence financial limits.

Consortiums can also carry on investments in material and, most of all, immaterial activities, and in projects with a higher risks, that would be difficultly faceable by an individual enterprise.

Investments for technological innovation, internationalization and communication can constitute an effective help for associates. However it's necessary that, besides a keen selection of the participants, also clear and shared rules are defined, for the consortium itself and the use of consorted goods and services.

This regulation should grant the consortium operative and decisional slenderness, though preserving a strong sense of participation for the associates and deterring opportunistic behaviors by the participants, that could mine the trust towards central organization and the associates themselves.

Trust is indeed a fundamental value in such organizations, in order to preserve a strategic medium term trend and to allow the enterprises to adhere to the politics decided within the consortium and delegate to it some strategic functions of their value chain.

Also the role of favoring equity links among the participants is not to be underestimated. The associates that with the time being have improved their reciprocal knowledge and uniformed some management processes can thus reduce the risks of informative asymmetry and integration, typical of the M\&A actions.

In this work a model is presented, allowing to analyze the main dynamics behind this phenomenon, by varying some core parameters.

A well established network can attract new players, that will probably bring new knowledge and competences in it.

The model is formally discussed in detail, and so the agents composing it. While studying quantitative results is beyond the purpose of this work, a qualitative analysis is briefly described, and the network graph, one of the graphical outputs supplied by the model, is analyzed: in order to show how network dynamics emerge from the model and its parameters, settable by the user.

The model is comprehensive and its scope is wide. In future works other features will be described in detail, and quantitative analysis will be carried on in order to study realworld cases (e.g.: existing industrial districts and so on) and the underlying dynamics that lead to their creations.

Besides, a new feature will be implemented in the model, referred to as "shock mode", allowing the user to stop the model at a given step, and change some inner parameter. For example, it will be possible to add a specific competence to one enterprise only, so that it's the only one in all the network possessing it. In that way it becomes possible to study how and based on which dynamics this specific competence spreads on the network and which kind of competitive advantage it gives, in terms of central position in the network and bargaining power to obtain other competences not possessed internally.
Another very interesting future research will regard the implementation of game-theoretical like dynamics into collaboration domain. The agents will be embedded with a form of reinforcement learning and will change their own strategy according to a perception, biased according to their original belief and predisposition.

\section{ACKNOWLEDGMENT}

The authors would like to gratefully acknowledge the key support of prof. Anna Maria Bruno, and prof. Gianpiero Bussolin, Full Professors of "Economia e Gestione delle Imprese" at the University of Turin.

\section{REFERENCES}

[1] G. Ahuja. "Collaboration Networks, Structural Holes and Innovation: A Longitudinal Study”. Administrative Science Quarterly, n. 45, pp. 425-455, 2000.

[2] W.E. Baker, R.R. Faulkner and G.A. Fisher. "Hazards of the Market: The Continuity and Dissolution of Interorganizational Market Relationships”. American Sociological Review, n. 63, pp. 147-177, 1998.

[3] R. Balaji, J. Koka and E. Prescott. "Designing alliance networks: the influence of network position, environmental change, and strategy on firm performance”. Strategic Management Journal, 29(6), pp. 639661, 2008

[4] J.A.C. Baum and P. Ingram. "Interorganizational learning and network organizations: Toward a behavioral theory of the 'interfirm”. In M. Augier and J.G. March (eds.) The Economics of Choice, Change and Organization: Essays in memory of Richard M. Cyert. Cheltenham UK: Edward Elgar. 2002, pp. 191-218.

[5] J.A.C. Baum, Rowley, T.J., Shipilov, A.V. and Chuang, Y-T. "Dancing with strangers: Aspiration performance and the search for underwriting syndicate partners”. Administrative Science Quarterly, n. 50, pp. 536-575, 2005.

[6] J.A.C. Baum, A.V. Shipilov and T.J. Rowley. "Where do small worlds come from?” Industrial and Corporate Change, n. 12, pp. 597-725, 2003.

[7] J.A.C. Baum, D. Van Liere and T.J. Rowley. "Between closure and holes: Hybrid network positions and firm performance”. Paper presented at the Academy of Management, Philadelphia PA, August. 2007.

[8] R. S. Burt. Structure Holes, Boston: Harvard University Press, 1982.

[9] R.S. Burt. Structural holes: The social structure of competition. Boston: Harvard University Press, 1992.

[10] R.S. Burt. “The network structure of social capital”. in R. I. Sutton and B. M. Staw (Eds.), Research in Organizational Behavior, n. 22:, pp. 339-365, 2000.

[11] A. S. Carrie. "From integration enterprises to regional clusters: the changing basis of competition”. Computer in Industry, Elsevier n. 42 (2-3), pp. 289-298, 2000.

[12] S.A. Chung, H. Singh, and K. Lee. "Complementarity, status similarity and social capital as drivers of alliance formation”. Strategic Management Journal, n. 21(1), pp. 1-22, 2000.

[13] D. Depperu. Economia dei consorzi tra imprese. Milano: Egea. 1996

[14] M. P. V. Dijk and A. Sverrisson. "Enterprise cluster in developing countries: mechanisms of transition an stagnation”. Entrepreneurship and Region Development, n. 15(3), pp. 183-206, 2003. 
[15] J.H. Dyer and H. Singh. "The relational view: Cooperative strategy and interorganizational sources of competitive advantage”. Academy of Management Review, n. 23, pp. 660-679, 1998.

[16] P. Evans and T:S: Wurstel. "Getting real about virtual commerce" in Harvard Business Review, Nov-Dec, 1999

[17] B. Gomes-Casseres. "Competitive advantage in alliance constellations”. Strategic Organization, n.1, pp. 327-335, 2003.

[18] M. Granovetter,. “The Strength of Weak Ties”. American Journal of Sociology, n. 78, pp. 1360-1380, 1973.

[19] M. Granovetter. "The Strength of Weak Ties: a Network Theory Revisited Sociological Theory”. Vol 1 1983, pp. 201-233 Reprinted in P.V. Marsden \& N. Lin (eds.) Social Structure and Network Analysis, Sage, 1982.

[20] M. Granovetter. "Economic action and social structure: the problem of embeddedness”. American Journal of Sociology, n. 91, 1985.

[21] R. Gulati. "Social Structure and Alliance Formation Patterns: A Longitudinal Analysis”. Administrative Science Quarterly, n. 4, 1995.

[22] R. Gulati. “Alliances and networks”. Strategic Management Journal, Special Issue n. 19(4), pp.293-317, 1998.

[23] R. Gulati. "Network location and learning: the influence of network resources and firm capabilities on alliance formation". Strategic Management Journal n. 20(5), pp. 397-420, 1999.

[24] R. Gulati and M. Gargiulo. "Where do interorganizational networks come from?”. American Journal of Sociology, n. 104(5), pp. 14391493, 1999.

[25] R. Gulati, N. Nohria and A. Zaheer. Strategic networks. Strategic Management Journal, n. 21(3), pp. 203-215, 2000.

[26] R. Gulati, D.A. Dialdin and L. Wang.. "Organizational networks.” in J.A.C. Baum (ed.), The Blackwell Companion to Organizations: pp. 281-303. Oxford: Blackwell Publishers, 2002.

[27] F. Harary and H.S. Wilf. "Mathematical aspect of electrical network analysis” SIAM-AMS (3), pp. 206, 1971.

[28] B. Levitt and J. G. March. “Organization learning”. Annual Review of Sociology, n. 14, pp. 319-340, 1988.

[29] S.X. Li and T.J. Rowley. "Locating capable and reliable allies: The role of experiential and nonexperiential information in interorganizational partner selection.” Presented at the Academy of Management Conference, Chicago, August. 1999.

[30] S.X. Li and T. J. Rowley. "Inertia and evaluation mechanisms in interorganizational partner selection: Syndicate formations among U.S. investment banks”. Academy of Management Journal, n. 45(6), pp. 1104-1119, 2002.

[31] A.M. Martinez and A. Sanchez. How "Cluster can encourage entrepreneurship an venture creation. Reasons and advantages”. International Entrepreneurship and Management Journal, Springer, n. 4 (3), pp. 315329, 2008.

[32] B. McEvily and A. Zaheer. Bridging "Ties: A Source of Firm Heterogeneity in Competitive Capabilities”. Strategic Management Journal, n. 20, pp. 1133-1156, 1999.

[33] J. L. Moreno. Who Shall Survive? Foundations of Sociometry, Group Psychotherapy and Sociodrama. New York: Beacon House, 1953.

[34] N. Nohria, The Differentiated Network: Organizing Multinational Corporations for Value Creation, San Francisco CA: Jossey-Bass Inc., 1997

[35] N. Nohria. "Introduction: Is the network perspective a useful way of studying organizations?” in N. Noria \& R. Eccles (Eds.), Network and Organizations: Structure, form and action. Boston: Harvard University Press, 1992, pp. 1-22
[36] D. Palmer. "Broken ties: Interlocking directorates and intercorporate coordination”. Administrative Science Quarterly, n. 28, pp. 40-55, 1983.

[37] J.M. Podolny. "Market uncertainty and the social character of economic exchange”. Administrative Science Quarterly, n. 39, pp. 458-470, 1994.

[38] J.M. Podolny. "Networks as the pipes and prisms of the market". American Journal of Sociology, n. 107, pp. 33-60. 2001

[39] W. W. Powell, K. W. Koput and L. Smith-Doerr. "Interorganizational collaboration and the locus of innovation: Networks of learning in Biotechnology”. Administrative Science Quarterly, 41, pp. 116-145, 1996.

[40] M. Remondino. "Agent Based Process Simulation and Metaphors Based Approach for Enterprise and Social Modeling”, ABS 4 Proceedings, SCS Europ. Publish. House, 2003.

[41] T.J. Rowley, J.A.C. Baum, A.V. Shipilov, H.R. Greve, and H. Rao. "Competing in groups. Managerial and Decision Economics”, n. 25, pp. 453-471. 2004.

[42] M. Ruef. "Strong ties, weak ties and island: structural and cultural predictors of organizational innovation”. Industrial an Corporate Change, Vol 11 (3), pp. 427-449, 2002.

[43] G. Simmel. The sociology of Georg Simmel (K. H. Wolff, Trans.). Glencoe, Ill. Free Press, 1950.

[44] D. Snow, L.A. Zurcher, S. Ekland-Olson (1980), "Social Networks and Social Movements: A Microstructural Approach to Differential Recruitment”. American Sociological Review, Vol. 45 pp.787 - 801, 1980.

[45] B. Uzzi and J. J. Gillespie. "Knowledge spillover in corporate financing networks: Embeddedness and the firm's debt performance”. Strategic Management Journal, 23: pp. 595-618. 2002.

[46] A. Valdani. L’impresa proattiva. Milano: Mc Graw Hill, 2000.

[47] G. Walker, B. Kogut and W. Shan. "Social capital, structural holes and the formation of an industry network". Organization Science, 8:, pp. 109-125, 1997.

[48] D. Willer. (ed.). Network Exchange Theory. New York: Praeger. 1999.

[49] S. Zhang, and X. Li. "Managerial ties, firm resources and performance cluster firms”. Asia Pacific Journal of Management, n. 25 (4) , pp. 615-633. 2008 